\title{
OCCUPATIONAL EXPOSURE TO ANTINEOPLASTIC DRUGS IN HOSPITAL ENVIRONMENTS: POTENTIAL RISK ASSOCIATED WITH CONTACT WITH CYCLOPHOSPHAMIDE- AND IFOSFAMIDE-CONTAMINATED SURFACES
}

\author{
Nicola Mucci ${ }^{1}$, Stefano Dugheri ${ }^{2}$, Andrea Farioli $^{3}$, Giacomo Garzaro ${ }^{4}$, Venerando Rapisarda ${ }^{5}$, \\ Marcello Campagna ${ }^{6}$, Alessandro Bonari ${ }^{1}$, Giulio Arcangeli ${ }^{1}$ \\ ${ }^{1}$ University of Florence, Florence, Italy \\ Department of Experimental and Clinical Medicine \\ ${ }^{2}$ Careggi University Hospital, Florence, Italy \\ Industrial Hygiene and Toxicology Laboratory, Occupational Medicine Unit \\ ${ }^{3}$ University of Bologna, Bologna, Italy \\ Department of Medical and Surgical Sciences \\ ${ }^{4}$ University of Turin, Turin, Italy \\ Department of Public Health and Pediatric Sciences \\ ${ }^{5}$ University of Catania, Catania, Italy \\ Department of Clinical and Experimental Medicine \\ ${ }^{6}$ University of Cagliari, Cagliari, Italy \\ Department of Medical Sciences and Public Health
}

\begin{abstract}
Background: Cyclophosphamide (CP) and ifosfamide (IP) contaminations have been detected in hospital environments. This study was conducted to determine if there was any contamination in the spaces (floors and door handles) between the hospital exit and the antineoplastic drugs (ADs) preparation and administration units. At the same time, the authors proposed a new automation of the analytical procedure to considerably decrease the time needed for sample preparation and analysis. Material and Methods: To evaluate the ADs contamination of surfaces, 829 wipe tests were performed in a campaign involving 3 hospitals located in Italy. Sampling was performed using an innovative kit. The levels of ADs were measured in each wipe sample using liquid chromatography/ triple quadrupole. Results: On-line solid-phase extraction guarantees the construction of a robust and reproducible analytical method. The CP and IP recoveries from stainless steel, polycarbonate and polyvinyl chloride ranged $>80 \%$, and the wipe holders and the automation tested ensured desorption efficiencies close to $100 \%$ for both the ADs. Of the 552 wipes taken on the spaces between the hospital exit and the preparation, administration and pharmacy warehouse units, 22 were greater than or equal to the limit of quantification, all adjacent to the administration units. Conclusions: This study provides an insight into the exposure situation against $\mathrm{ADs}$ residues. In order to improve environmental monitoring programs, the authors propose to evaluate the ADs contamination also outside the preparation, administration and pharmacy warehouse units. Med Pr. 2020;71(5):519-29
\end{abstract}

Key words: occupational exposure, cyclophosphamide, antineoplastic drugs, ifosfamide, wipe test, surface contamination

Corresponding author: Stefano Dugheri, Careggi University Hospital, Industrial Hygiene and Toxicology Laboratory, Occupational Medicine Unit, Largo Giovanni Alessandro Brambilla 3, I-50134 Florence, Italy, e-mail: stefano.dugheri@unifi.it

Received: 10 September 2019, accepted: 27 April 2020

\section{INTRODUCTION}

Occupational exposure of healthcare workers to antineoplastic drugs (ADs) has been studied since the 1970s [1]. Ifosfamide (IP) and cyclophosphamide (CP) are commonly used oxazaphosphorines. To cause cell death, the alkylating agents $\mathrm{CP}$ and IP, as prodrugs, required biotransformation into their metabolic products to interact with DNA; only CP is recognized as carcinogenic to humans by the International Agency for
Research on Cancer. Studies have revealed that adverse health outcomes, such as genetic damage [2], reproductive effect or miscarriages [3], can be associated with occupational exposure to ADs. In Italy, the consumption of CP and IP exceeds $500 \mathrm{~kg} / \mathrm{year}$ and is second to that of 5-fluorouracil [4].

Since 2004, the European community has promoted the implementation of administrative and engineering controls across member states, in order to provide healthcare workers with the highest protection, and to 
warrant the use of appropriate and validated procedures for handling hazardous drugs. In February 2019, the European Parliament approved amendments to Directive 2004/37/CE on carcinogens and mutagens and their implications for the healthcare sector (the Carcinogens and Mutagens Directive) [5]. Recommendation No. 11 from "Preventing occupational exposure to cytotoxic and other hazardous drugs. European Policy Recommendations" puts an effort into the use of environmental monitoring procedures to detect how the drugs in question are released and spread, and thus to control and improve the effectiveness of protective measures and equipment [6].

Recently, the European Biosafety Network has published a brochure in 8 languages on the amendments where a value of $0.1 \mathrm{ng} / \mathrm{cm}^{2}$ of the surface threshold contamination is recommended for ADs [7]. Until today, several manuscripts [8-10] have been published showing that ADs were detected in urine samples of healthcare workers employed in preparation and administration units. The dermal absorption is the major exposure route [11]; direct contact with the drugs (manipulate vials producers and/or pharmacological solutions in intravenous bags), or indirect contact as a result of touching contaminated surfaces, could be considered the main routes of dermal exposure. By performing wipe sampling on the exposed surfaces, the potential risk for dermal contact can be monitored. In addition, in January 2019, the American Conference of Governmental Industrial Hygienists (ACGIH) firstly introduced a new category of the limit value referred to surface contamination, called the threshold limit value - the surface level. Surface limits for ADs are still not proposed by ACGIH but the need to quantitate harmful substances in order to control and reduce the contact from surfaces is now considered and ruled about.

Conflicting results concerning the relationship between surface ADs contamination and professional exposure are reported in literature [12]. Consequently, no exposure limits for ADs are proposed by any governmental industrial hygiene association since there are no clear exposure levels known. Instead, the "as low as reasonably achievable" principle is applied, but the maximum exposure reduction cannot be demonstrated without the quantitative proofs of environmental contamination. To guarantee the accuracy of ADs exposure evaluation, both in occupational and domestic scenarios, Kromhout [13] recommended a quantitative exposure assessment. Consequently, independent guidelines based on the percentile values for several ADs were sug- gested by several authors [14-16] with the aim of monitoring compliance with procedures, cleaning effectiveness, and pollution's persistency over time. Actually, ADs contamination in hospital environments and on equipment is the consequence of their massive use $[17,18]$. Moreover, patients can carry ADs contamination in domestic scenarios [19], and it eventually involves not only surfaces in the house environment but also the soil and superficial water [20]. Hamscher et al. [21] have shown that there might be a potential contamination risk when administering ADs in veterinary medicine. In a healthcare environment, ADs contamination can be present both in preparation units, due to pure drugs handling, and in administration units.

To evaluate the ADs carry-over, the authors of this study performed an analysis of wipe test results focusing on the spaces between the hospital exit and the preparation, administration and pharmacy warehouse units. At the same time, they proposed a new automation of the analytical process that leads to a reduction of time for sample preparation and analysis.

\section{MATERIAL AND METHODS}

\section{Experimental design}

In this study, the authors conducted the ADs environmental assessment based on 829 wipe samplings performed in 3 hospitals located in Italy in 2018. Generally, ADs contamination was estimated by wiping $400 \mathrm{~cm}^{2}$ surfaces of the floor, handles or other plain areas where healthcare workers and oncologic patients involved in therapies could eventually determine an unwanted drug spread. Thus, these findings proved helpful in identifying the potential sources or routes of accidental exposure.

In particular, the sampling included:

- floors and handles of exit doors between the preparation, administration and pharmacy warehouse units, and the hospital hall (552 wipes);

the administration units, and in particular floors and handles of exit doors, nurses' gloves, drip rods, and the outer surface of ADs infusion sacks (277 wipes). Wipes were sampled at the beginning (B) and at the end (E) of the work shift (WS) for 3 consecutive days in a week.

Moreover, wipe tests were taken from the surface of 25 drug vials and on related primary packaging of CP (Endoxan powder form, $1 \mathrm{~g}$, batch 8D158B, Baxter) and IP (Holoxan powder form, $1 \mathrm{~g}$, batch 8E076A, Baxter). The surfaces of the vials had been removed from 
the primary packaging just before the wipe tests were performed.

The volume of ADs administration units ranged 13 076-19 096 therapies per hospital in a year. Italian hospitals follow the national guidelines [22]:

- the staff were skilled in safety equipment and maintenance, research updates, and emergency care;

- to avoid any leak of hazardous substances (ChemoClave, ICU Medical Inc.; CareFusion, Becton Dickinson; Cyto-Set, B-Braun) closed-system devices were introduced;

specific cleansers were employed for floors (a solution of $0.2 \%$ Marseille soap, then a cleaning step with $0.115 \%$ sodium hypochlorite, and finally $70 \%$ ethanol) and for smaller areas (Alcavis Bleach-Wipe 1:50, Angelini Pharma Inc.). Four IIA-2 class biosafety cabinets were at the centralized ADs preparation units, which were protected by an anteroom. The levels of CP and IP were measured in each wipe sample by liquid chromatography (LC) and triple quadrupole (TQ) mass spectrometry (MS/MS) instruments.

\section{Wipe sampling}

In this study, the authors developed a new wipe test kit, as previously described [14,23], which includes all the equipment required for sampling (Figure 1): nonwoven fabric wipes soaked with a water/methanol solution, put in a wipe cartridge kit (WCK) with a GH Polypro filter, tweezers with disposable pipette tips, and a handbook in which the wipe sampling technique is described. On plain surfaces, a $20 \times 20 \mathrm{~cm}$ area was wiped in 3 directions, while smaller areas were wiped recording the exact sampled surface. The wipe was eluted using $2 \mathrm{ml}$ of a water/methanol solution with internal standards, and it was put into the WCK using Automated Wipe Desorption (Chromline) mounted on a Flex GC autosampler (EST Analytical) equipped with WCK trays and a $2.5 \mathrm{ml}$ headspace syringe.

\section{Analytical procedures}

First, CP and IP purification was performed with an Oasis Hydrophilic Lipophilic Balance (HLB) $25 \mu \mathrm{m}$, $2.1 \mathrm{~mm}$ internal diameter, $20 \mathrm{~mm}$ length column (Waters, ref. 186002036) used as on-line solid-phase extraction (SPE) and coupled to the Alliance e2695 Selector Valve (Waters) (Figure 2), installed on LC-Quattro Micro (Waters) TQ-MS/MS. The ADs separation procedure was performed with an Atlantis T3, $3 \mu \mathrm{m}$ $2.1 \times 100 \mathrm{~mm}$ column (Cat. No. 186003718, Waters)
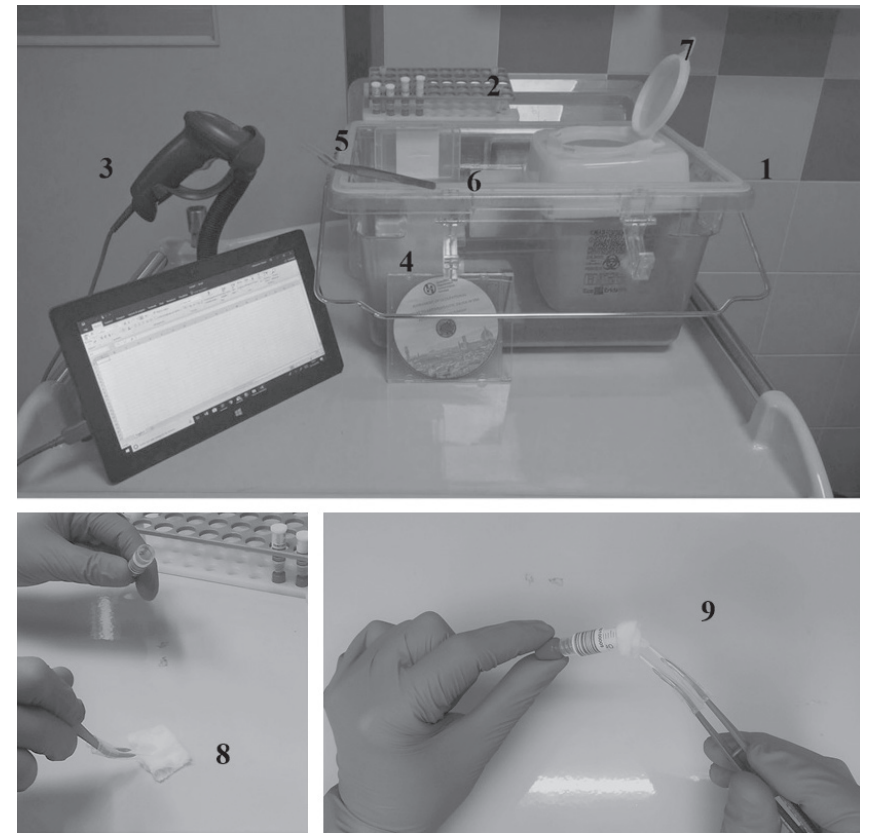

1 - safe transport box, 2 - wipe cartridge kit (WCK), used for automatic desorption, preassembled with $5 \times 5 \mathrm{~cm} 3$-layer nonwoven fabric with 50 -position WCK trays, 3 - tablet with a barcode reader, 4 - CD instruction manual with photos and a video on the correct technique for obtaining wipe samples, 5 - tweezers with a joint for disposable pipette tips, 6 - tweezer tips, 7 - tweezer tip waste container, 8 - wipe sampling of a surface in laminar flow hood, 9 - wipe insertion in a bar-coded WCK after the surface sampling.

Figure 1. Wipe sampling kit used in a campaign involving 3 hospitals located in Italy in 2018

at $25^{\circ} \mathrm{C}$. The gradient (a $0.1 \%$ formic acid solution [A] and a $0.1 \%$ formic acid in 60:40 acetonitrile:methanol solution [B]) used for chromatographic separation is shown in Table 1 . The flow rate was $0.3 \mathrm{ml} / \mathrm{min}$ and $100.0 \mu \mathrm{l}$ of the injection volume was set for desorbed wipes. The MS utilized multiple reaction monitoring (MRM) and positive electrospray ionisation (ESI+) for CP precursor $\mathrm{m} / \mathrm{z} 261.19>$ product $\mathrm{m} / \mathrm{z} 106.01$, IP $261.20>92.00$, daunorubicin (internal standard, IS) $528.26>321.12$, trophosphamide (IS) $323.21>154.02$, cephalomannine (IS) $832.49>264.19$.

\section{Validation study}

The calibration curve was carried out by analyzing wipes doped with mixed standard solutions of IP and $\mathrm{CP}$ at 6 concentration levels $(1.25,2.5,5.0,10.0,20.0$, and $40 \mathrm{ng} /$ wipe), blank wipe samples and wipes spiked with the IS solution only. Five replicates of each level were performed, and the curve was obtained by plotting the peak area ratio between each analyte and IS, vs. the nominal concentration of each calibration level. To obtain the best function between the calibration levels, a linear regression approach was performed. 

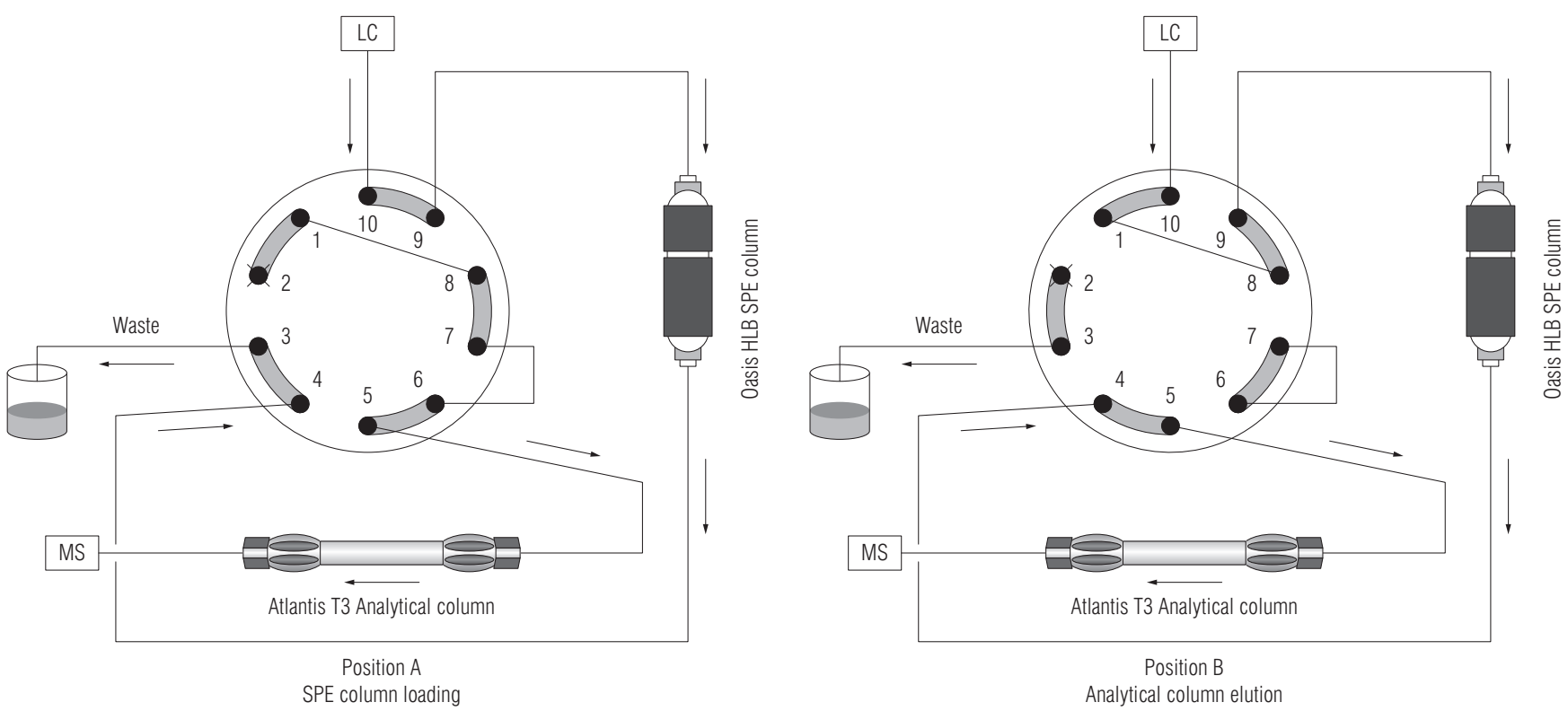

MS - mass spectrometer.

Position A of the valve is set for on-line solid phase extraction (SPE) sample loading and to discharge hydrophilic and ionic compounds washing in the waste. After 4 min of runtime, position B is set for SPE sample elution and chromatographic separation by the analytical column.

Figure 2. The mobile phase from liquid chromatography (LC) flows into the Selector Valve (Waters) after the sample injection - the system employed in the analysis of wipe sampling performed in a campaign involving 3 hospitals located in Italy in 2018

The slopes ( $\mathrm{m}$ ) and intercepts (b) of the calibration lines were calculated with the least-squares linear regression analysis, using the following equation:

$$
y=m x+b
$$

where:

$y$ - ratio between the chromatographic area of the analyte and its IS,

$\mathrm{x}$ - analyte concentration.

The limit of detection (LOD) was estimated as:

$$
\mathrm{LOD}=\left(3 \mathrm{SE}_{\mathrm{b}}+\mathrm{b}\right) / \mathrm{m}
$$

where:

$\mathrm{SE}_{\mathrm{b}}$ - intercept standard error.

The limit of quantification (LOQ) was obtained using $10 \mathrm{SE}_{\mathrm{b}}$, which corresponds to 3.3 LOD. Method repeatability was verified in terms of precision from within- and inter-session standard analysis. Ten replicates of low- $(2 \mathrm{ng} / \mathrm{ml})$ and high-level $(20 \mathrm{ng} / \mathrm{ml})$ standards were performed, and the relative coefficient of variation $(\mathrm{CV})$ on the same day was reported as within-session repeatability. Inter-session repeatability was thus estimated by CV from daily results of 3 low- and high-level standards replicates for 10 days.
Accuracy was determined on the same day by mean recoveries of 10 low- and high-level standard replicates, reported as the percentage ratio between the revealed and nominal concentrations. To validate method accuracy, it was tested using the U.S. Food and Drug Administration requirements. Low- and high-level standards were analyzed in every session from a new CP and IP solution with internal standards to assure the validation of results in the analytical session.

Then, ADs wipe sampling recoveries were estimated as the percentage of decontamination from doped surfaces. The authors also analyzed samples $\left(0.05 \mathrm{ng} / \mathrm{cm}^{2}\right.$ and $0.4 \mathrm{ng} / \mathrm{cm}^{2}$ ) from stainless steel, smooth and less smooth $20 \times 20 \mathrm{~cm}$ plates, doped with $20 \mathrm{ng}$ and $100 \mathrm{ng}$ of ADs, respectively, and diluted 1:5 with a water/methanol solution (50:50) before the injection, in order to be compliant with the calibration curve. The stableness of the spiked wipe was evaluated at $4^{\circ} \mathrm{C}$ between $4-24 \mathrm{~h}$. Wipe desorption efficiency was estimated as the difference of response between the doped wipes and the tested nominal ADs solution. The matrix effect was also evaluated for each $\mathrm{AD}$, as a mean relative ionisation recovery for the analytes, calculating the response decline percentage between the analytes spiked into the eluate, after blank wipe extraction, and the analyte directly injected into the mobile phase. The Stata data analysis and statistical software (StataCorp LLC) were utilized to manage the obtained resulting data. 
Table 1. Selector Valve (Waters) position for on-line solid phase extraction (SPE) loading and elution gradient for liquid chromatographic separation performed in a campaign involving 3 hospitals located in Italy in 2018

\begin{tabular}{lcccc}
\hline & $\begin{array}{c}\text { Time } \\
{[\mathrm{min}]}\end{array}$ & & $\begin{array}{c}\text { Phase } \\
{[\%]}\end{array}$ & Selector Valve position \\
\cline { 2 - 4 } & & $\mathrm{A}$ & $\mathrm{B}$ & $\mathrm{A}$ \\
$0.0-4.0$ & 95 & 5 & $\mathrm{~B}$ \\
$4.1-7.0$ & 60 & 40 & $\mathrm{~B}$ \\
$7.1-11.0$ & 40 & 60 & $\mathrm{~B}$ \\
$11.1-17.0$ & 15 & 85 & $\mathrm{~B}$ \\
$17.1-21.0$ & 100 & 0 & $\mathrm{~B}$ \\
\hline
\end{tabular}

A $-0.1 \%$ formic acid solution, B $-0.1 \%$ formic acid in $60: 40$ acetonitrile:methanol solution.

\section{RESULTS}

\section{Wiping and desorption}

The wiping procedure utilized in this study, based on the use of tweezers instead of gloves, as was done by other authors, allows to a reduce the sampling time, cost (as replaceable tips used with the tweezers are cheaper than gloves), and the contamination risk. The CP and IP recoveries from stainless steel, polycarbonate and polyvinyl chloride were $>80 \%$. Inserting the wipes into the holder and automating the procedure assured desorption efficiencies close to $100 \%$.

\section{Analyses}

The on-line SPE by OASIS HLB was used instead of the conventional C18-cartridge SPE due to its better chemical stability in extreme $\mathrm{pH}$ conditions. Furthermore, the polymeric column sustained lower back pressure than the silica sorbent, and this characteristic must be considered in the method development in order to safeguard the column performance. For all the test compounds, the analytical curves proved linear in the whole concentration range, with correlation coefficients $\left(\mathrm{r}^{2}\right)>0.99$. The intra- and inter-day variability for all compounds ranged $3.5-7.5 \%$, and the average intra-day accuracies were sufficient. The LOQs equaled 0.270 and $0.217 \mathrm{ng} /$ wipe for CP and IP, respectively (Table 2).

\section{Data distribution}

Of the 552 wipes taken on the floors and door handles of the spaces between the hospital exit and the preparation, administration and pharmacy warehouse units, 22 were $\geq$ LOQ (4\%), all adjacent to the ADs administration units; of these, 4 were taken at B-WS and 18 at E-WS. Positive determinations (6\% for a total of 277 wipe tests) for at least $1 \mathrm{AD}$ at B-WS (No. 3) and at E-WS (No. 14) were determined on samples taken from the administration units: in detail, drip rods (No. 2), nurse call buttons (No. 1) and the floor, tap, and toilet seat of the bathrooms (No. 14). Also, as regards the administration units, no positive $\mathrm{CP}$ and IP determinations were detected on the gloves of the nurses, the floor under the drip rods, and the outer surface of the ADs sacks before and after the infusion (Table 3).

\section{Surface contamination of CP and IP packaging}

Certain amounts of IP (ranging 6.7-44.2 $\mathrm{pg} / \mathrm{cm}^{2}$ ) were found on the surfaces of all the vials investigated that had been removed from the outer package. No CP and IP were found on the investigated primary packaging.

\section{DISCUSSION}

Nowadays, the sensitivity and specificity of analytical methods are not enough to detect ADs [12,24]. The authors of this study proposed the wipe test, a method largely used by industrial hygienists and the unique method that can detect ADs at low concentrations, as $\mathrm{pg} / \mathrm{cm}^{2}$. Preceding studies showed that solvents and clean-up steps were often used to extract and eliminate interfering substances from the wipe test [12]. This process requires many manual operations and it causes uncertainty of the determination, higher costs and a possible analyte loss. Therefore, the authors developed a method that combined the on-line SPE qualities with the LC-MS/MS quantitation.

The interest in simultaneous determinations of ADs, using chromatographic separation, has grown in recent years within the scientific community $[25,26]$. The authors proposed the use of the Atlantis T3 LC analytical column. It is a silica-based, reversed-phase C18 column that provides equalized retention of low-polar and non-polar compounds: trifunctional C18 alkyl phase promotes polar compound retention and aque- 
Table 2. Calibration curve parameters and the limit of detection (LOD) and the limit of quantification (LOQ) for cyclophosphamide (CP) and ifosfamide (IP) in wipe samples carried out in a campaign involving 3 hospitals located in Italy in 2018

\begin{tabular}{|c|c|c|}
\hline Variable & Cyclophosphamide & Ifosfamide \\
\hline Molecular weight $[\mathrm{g} / \mathrm{mol}]$ & 261.08 & 261.09 \\
\hline \multicolumn{3}{|l|}{ Ion $[\mathrm{m} / \mathrm{z}]$} \\
\hline precursor ion & 261.19 & 261.20 \\
\hline quantitative product & 106.01 & 92.26 \\
\hline qualitative product & 140.21 & 182.12 \\
\hline \multicolumn{3}{|l|}{ Least-squares linear regression parameters } \\
\hline $\mathrm{m}$ & 84.39 & 65.15 \\
\hline $\mathrm{b}$ & 0.31 & 0.17 \\
\hline Coefficient of correlation & 0.99 & 0.99 \\
\hline \multicolumn{3}{|l|}{ Limit of detection (LOD) } \\
\hline ng/wipe & 0.082 & 0.066 \\
\hline $\mathrm{pg} / \mathrm{cm}^{2}$ & 0.2 & 0.1 \\
\hline \multicolumn{3}{|l|}{ Limit of quantification (LOQ) } \\
\hline ng/wipe & 0.270 & 0.217 \\
\hline $\mathrm{pg} / \mathrm{cm}^{2}$ & 0.6 & 0.5 \\
\hline Within-session accuracy (10 replicates, 2 levels ${ }^{\star}$ ) & 7.7 & 3.8 \\
\hline Within-session repeatability (10 replicates) & 3.5 & 5.8 \\
\hline Inter-session repeatability ( 3 replicates, 2 levels ${ }^{\star}$ ) & 7.5 & 4.8 \\
\hline
\end{tabular}

Within-session accuracy, precision of the assay in terms of within- and inter-session repeatability are reported as the coefficient of variation (CV) and the number of lowand high-level standards replicates

* $2 \mathrm{ng} / \mathrm{ml}$ and $20 \mathrm{ng} / \mathrm{ml}$.

ous mobile phase compatibility. Its on-line coupling with the Oasis HLB clean-up cartridge offers an analytical innovation: thanks to the use of the Selector Valve developed by Waters, it is possible to load, elute and inject the sample into the LC with the sole aid of the chromatographic system pumps, without the need to install external pumps. This approach guarantees the construction of a robust and highly reproducible method. In particular, the Oasis HLB allows to elute, by modifying the $\mathrm{pH}$ of the mobile phase, a substance with different pKa. Compared to other methods, the on-line SPE allows a lower consumption of solvents, a reduction in the cost of disposal of conventional SPE cartridges, and a reduced use of operator time.

The XYZ robotic system reduces manual operations and enables automated wipe desorption. Using bar-coded WCK, each wipe was traced by a unique tracking number. Moreover, using a data management system (Bika LIMS), all the information concerning the sampling process, analysis and quantitation can be integrated.

The main aspects concerning the risk to healthcare workers are about the ADs toxicity and how these drugs can enter the body. In fact, ADs environmental monitoring has been suggested by different guidelines released by international organizations, as the Occupational Safety and Health Administration and the European Policy Recommendation [6].

Generally, drugs with a low molecular weight $(<500 \mathrm{Da})[11]$ are the most inclined to dermal absorption. While reviewing literature, it was found that a dermal occupational exposure limit was proposed for CP, equal to $4000 \mathrm{pg} / \mathrm{cm}^{2}$ [19]. Data from animal studies show that the risk of developing cancer was 100-600 per million [27]. For the quantitative evidence of environmental CP and IP contaminations, a traffic-light color-coding reference values model was proposed by Sessink [16], while Kiffmeyer et al. [15] developed an independent guideline based on the 90th percentile values of 8 ADs. Hedmer et al. [28] and Sottani et al. [29] suggested hygienic guidance values (HGVs) for different kinds of surfaces at hospital. Finally, Dugheri et al. [14,23] recommended both HGVs and surface exposure levels (SELs), respectively, based on the percentile of wipe sampling data distributions (Table 4). 


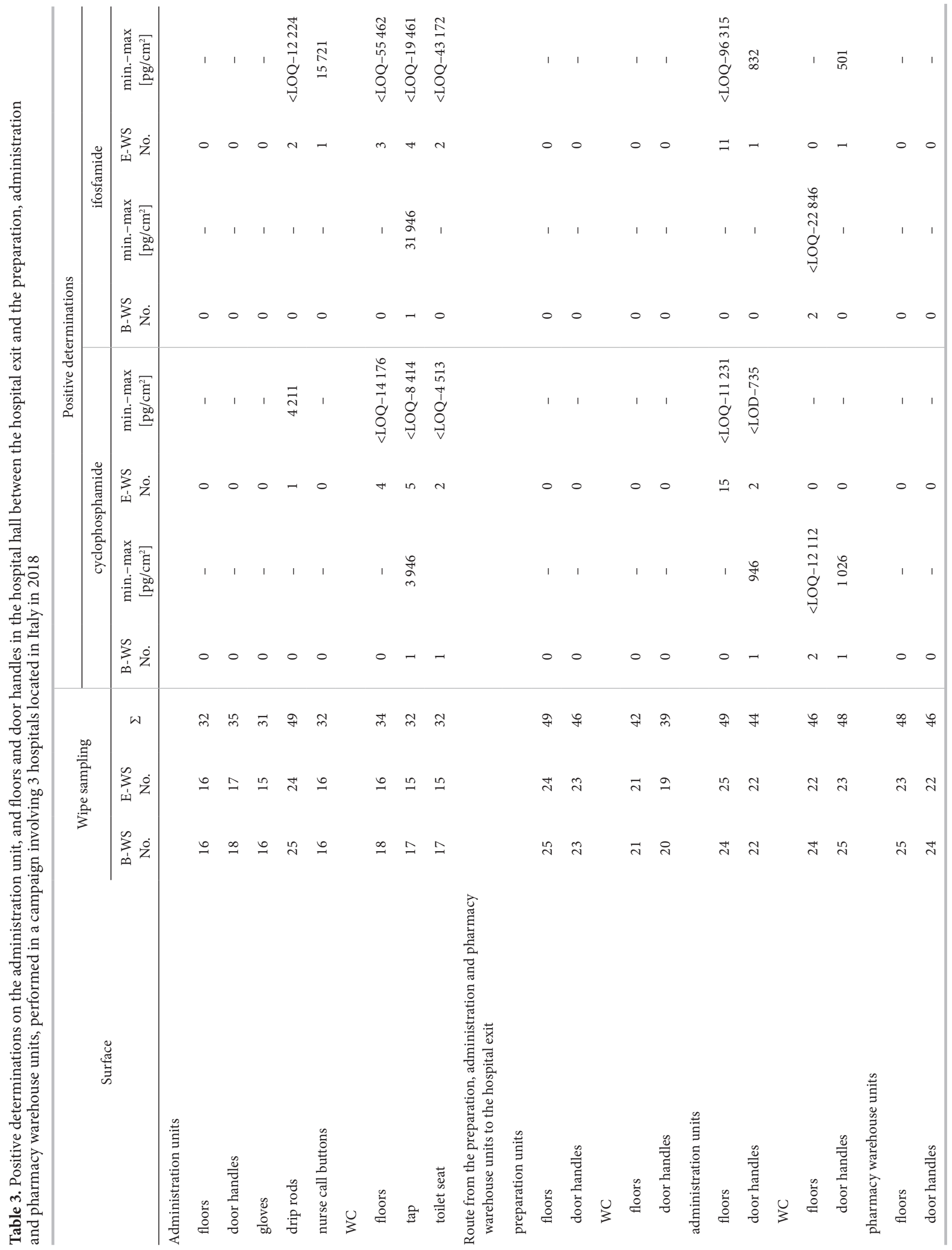




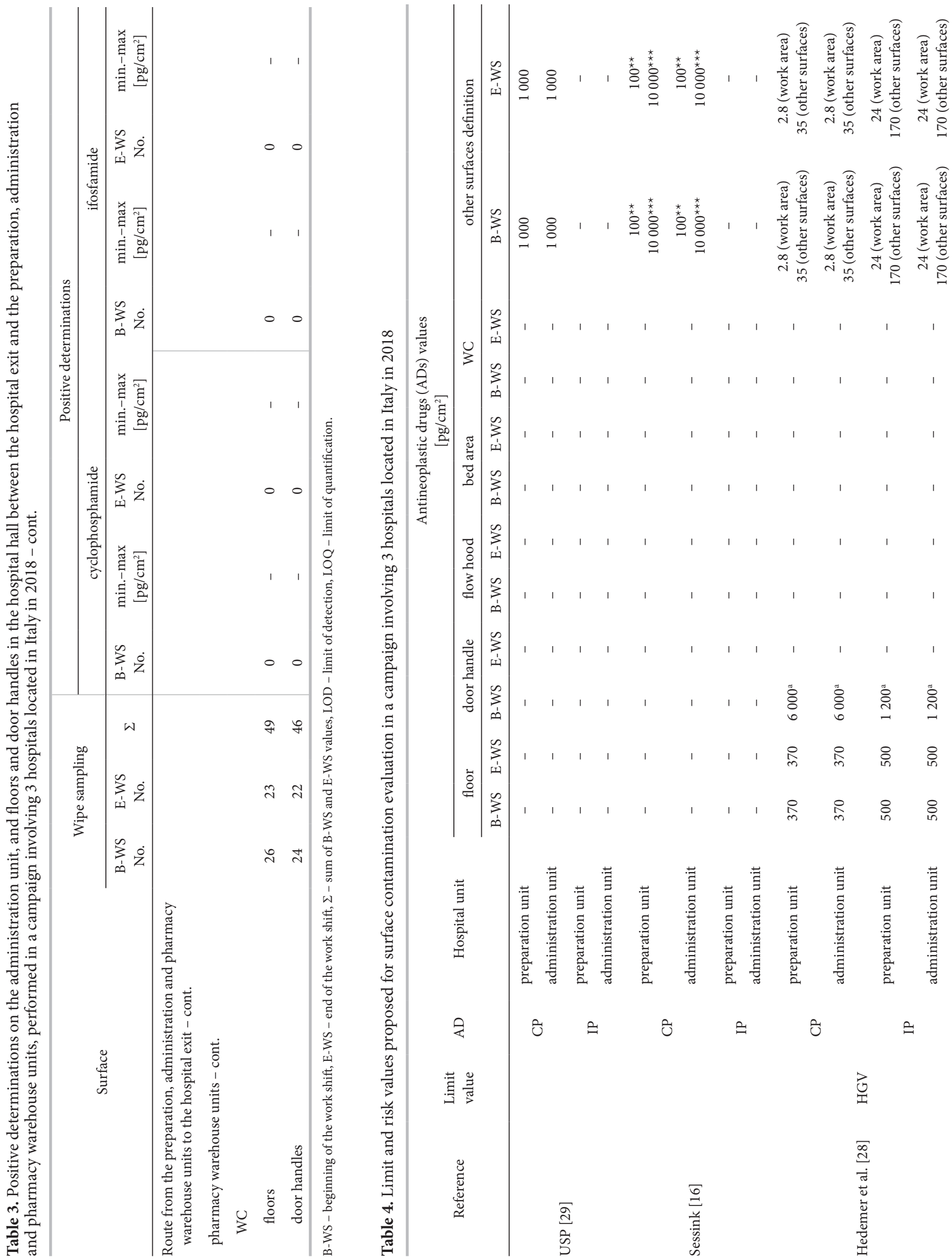




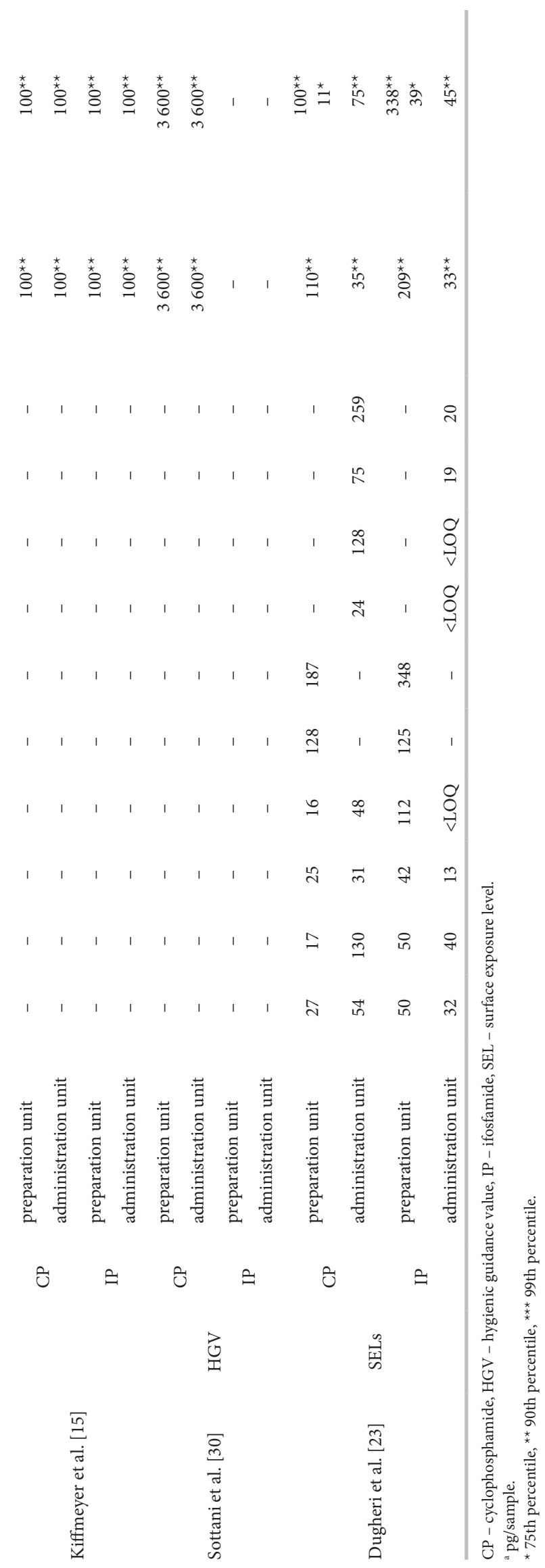

The authors of this study considered the floors and door handles of the locations outside the ADs preparation, administration and pharmacy warehouse units in order to analyze the contamination containment, and to identify the possible routes of the substance migration through the preparation, distribution and administration scenarios. These ubiquitous environmental contaminations could lead to the exposure of workers who are not directly involved in ADs administration or preparation. This kind of interaction represents a potential hazard for these employees that generally use less protective clothing [30]. In these campaigns, the results showed that positive wipe tests for CP and IP were revealed on the spaces between the hospital exit and the administration units; a percentage similar to that found 10 years ago [14,23], or currently by other authors [31], in the preparation and administration units. No contamination from CP and IP was detected in the adjacent spaces to the preparation and pharmacy warehouse units, demonstrating that the internal procedures were complied with. In the administration units, the patient represents a variable that is still difficult to control and nurses may have difficulty managing [32].

\section{CONCLUSIONS}

This study gives an overview of exposure to ADs residues in the spaces adjacent to the administration rooms. In the authors' opinion, there is a need to:

adopt certain procedures to help patients contain the contamination of ADs,

extend the protocol of cleaning of the administration units also to adjacent spaces of the hospital outbound path,

introduce new sampling points by wipe tests also in the adjacent areas of the preparation, administration and pharmacy warehouse units.

Furthermore, another potential source of exposure to $\mathrm{ADs}$ was investigated: unbroken $\mathrm{CP}$ and IP drug vials, and their outer packaging were tested. This contribution showed that only small IP quantities were found on vial surfaces removed from the outer package. Thanks to this study, it was found that the clean-up processes and manufacturing are key steps of ADs handling for preventing contamination at hazardous levels.

Based on this experience, the authors recommend that patients must be made conscious of the potential risk for other people, considering that the contamination of IP and CP can be revealed on all types of sur- 
faces. Moreover, for this reason, hygienic and protective protocols should also be introduced for the domestic environment to reduce the risk of exposure.

Professor Andrea Farioli (1981-2020), M.D., Ph.D., a brilliant colleague and a sincere friend, suddenly passed while he was performing significant epidemiological research on the SARS-CoV-2.

\section{REFERENCES}

1. Falck K, Gröhn P, Sorsa M, Vainio H, Heinonen E, Holsti LR. Mutagenicity in urine of nurses handling cytostatic drugs. Lancet. 1979;1(8128):1250-1, https://doi.org/10.1016/ s0140-6736(79)91939-1.

2. Cavallo D, Ursini CL, Perniconi B, Di Francesco A, Giglio M, Rubino FM, et al. Evaluation of genotoxic effects induced by exposure to antineoplastic drugs in lymphocytes and exfoliated buccal cells of oncology nurses and pharmacy employees. Mutat Res. 2005;587:45-51, https://doi. org/10.1016/j.mrgentox.2005.07.008.

3. Dranitsaris G, Johnston M, Poirier S, Schueller T, Milliken D, Green E, et al. Are health care providers who work with cancer drugs at an increased risk for toxic events? A systematic review and meta-analysis of the literature. J Oncol Pharm Pract. 2005;11:69-78, https://doi. org/10.1191/1078155205jp155oa.

4. Fugnoli L. [Monitoring of contamination by antineoplastic drugs in hospital]. Milan: University of Milan, Occupational Medicine and Industrial Hygiene; 2011. Italian.

5. Directive 2004/37/ec of the European Parliament and of the council of 29 April 2004 on the protection of workers from the risks related to exposure to carcinogens or mutagens at work (Sixth individual Directive within the meaning of Article 16(1) of Council Directive 89/391/EEC). Off J Eur Union L 158 (Apr 30, 2004).

6. European BioSafety Network [Internet]. 2016 [cited 2019 Aug 1]. Preventing occupational exposure to cytotoxic and other hazardous drugs European Policy Recommendations. Available from: https://www.europeanbiosafetynetwork.eu/wp-content/uploads/2016/05/Exposure-to-Cytotoxic-Drugs_Recommendation_DINA4_10-03-16.pdf.

7. European BioSafety Network [Internet]. 2019 Amendments to the Carcinogens and Mutagens Directive (CMD). The Network; 2019 [cited 2019 Aug 1]. Available from: https://www.europeanbiosafetynetwork.eu/wp-content/ uploads/2019/03/Amendments-to-CMD3-and-implications.pdf.

8. Dhersin A,AtgéB,MartinezB,TitierK,RoussetM,SidattCheikh El Moustaph M, et al. Biomonitoring of occupational exposure to 5 -FU by assaying $\alpha$-fluoro- $\beta$-alanine in urine with a highly sensitive UHPLC-MS/MS method. Analys. 2018;143(17): 4110-7, https://doi.org/10.1039/c8an00479j.

9. Izzo V, Charlier B, Bloise E, Pingeon M, Romano M, Finelli A, et al. A UHPLC-MS/MS-based method for the simultaneous monitoring of eight antiblastic drugs in plasma and urine of exposed healthcare workers. J Pharm Biomed Anal. 2018;154:245-51, https://doi.org/10.1016/ j.jpba.2018.03.024.

10. Mathias PI, Connor TH, B'Hymer C. A review of high performance liquid chromatographic-mass spectrometric urinary methods for anticancer drug exposure of health care workers. J Chromatogr B Analyt Technol Biomed Life Sci. 2017;1060:316-24, https://doi.org/10.1016/j.jchromb. 2017.06.028.

11. Connor TH. Hazardous anticancer drugs in health care: environmental exposure assessment. Ann N Y Acad Sci. 2006;1076:615-23, https://doi.org/10.1196/annals.1371.021.

12. Kibby T. A review of surface wipe sampling compared to biologic monitoring for occupational exposure to antineoplastic drugs. J Occup Environ Hyg. 2017;14(3):15974, https://doi.org/10.1080/15459624.2016.1237026.

13. Kromhout H. Hygiene without numbers. Ann Occup Hyg. 2016;60:403-4, https://doi.org/10.1093/annhyg/mev096.

14. Dugheri S, Bonari A, Pompilio I, Boccalon P, Mucci N, Arcangeli G, et al. A new approach to assessing occupational exposure to antineoplastic drugs in hospital environments. Arh Hig Rada Toksikol. 2018;69(3):226-37, https://doi.org/10.2478/aiht-2018-69-3125.

15. Kiffmeyer TK, Tuerk J, Hahn M, Stuetzer H, Hadtstein C, Heinemann A, et al. Application and assessment of a regular environmental monitoring of the antineoplastic drug contamination level in pharmacies - the MEWIP project. Ann Occup Hyg. 2013;57:444-55, https://doi. org/10.1093/annhyg/mes081.

16. Sessink PJ, editor. Environmental contamination with cytostatic drugs: past, present and future [Internet]. Fall: Safety Consideration in Oncology Pharmacy (Special edition); 2011 [cited 2019 Aug 1]. Available from: https:// pdfs.semanticscholar.org/8652/4d606dbd8e116ca2c26b1ec70d3f81cfe272.pdf.

17. Negri S, Oddone E, Morandi F, Sottani C, Gardinali F, Lillo A, et al. Validation of cleaning procedures used in an Italian Hospital Pharmacy for antineoplastic drug decontamination: a new tool for industrial hygiene. Med Lav. 2019;110(2):93-101, https://doi.org/10.23749/mdl. v110i2.8001.

18. Federici M, Raffaelli J, Paolucci D, Schierl R, Krämer I. Efficacy of four cleaning solutions for the decontamination of selected cytotoxic drugs on the different surfaces 
of an automated compounding system. J Occup Environ Hyg. 2019;16(1):6-15, https://doi.org/10.1080/15459624. 2018.1526384.

19. Böhlandt A, Sverdel Y, Schierl R. Antineoplastic drug residues inside homes of chemotherapy patients. Int J Hyg Environ Health. 2017;220(4):757-65, https://doi. org/10.1016/j.ijheh.2017.03.005.

20. Furtak-Niczyporuk M, Jaroszyński J, Mela A, Staniszewska A, Piotrowska J, Zimmermann A, et al. [Cytostatic and cytotoxic waste-rules of conduct in Poland]. Med Pr. 2019;70(3):377-91, https://doi.org/10.13075/mp.5893. 00827. Polish.

21. Hamscher G, Mohring SA, Knobloch A, Eberle N, Nau H, Nolte I, et al. Determination of drug residues in urine of dogs receiving anti-cancer chemotherapy by liquid chromatography-electrospray ionization- tandem mass spectrometry: is there an environmental or occupational risk? J Anal Toxicol. 2010;34(3):142-8, https://doi.org/10.1093/jat/34.3.142.

22. Ministero della Sanità. [Guideline document for the safety and greeting of workers exposed to antiblastic chemotherapy in the healthcare environment. (Directory of acts No. 736). (G.U. General Series n.236 of 07-10-1999)]. Gazzetta Ufficiale; 1999. Italian.

23. Dugheri S, Bonari A, Pompilio I, Boccalon P, Tognoni D, Cecchi $\mathrm{M}$, et al. Analytical strategies for assessing occupational exposure to antineoplastic drugs in healthcare workplaces. Med Pr. 2018;69(6):589-604, https://doi.org/ 10.13075/mp.5893.00724.

24. Dugheri S, Bonari A, Pompilio I, Gentili M, Montalti M, Mucci N, et al. A new automated gas chromatography/solid phase microextraction procedure for determining $\alpha$-fluoro$\beta$-alanine in urine. Malaysian J Anal Sci. 2017;21:1091-100, https://doi.org/10.17576/mjas-2017-2105-11.

25. Guichard N, Fekete S, Guillarme D, Bonnabry P, Fleury-Souverain S. Computer-assisted UHPLC-MS meth- od development and optimization for the determination of 24 antineoplastic drugs used in hospital pharmacy. J Pharmaceut Biomed. 2019;164:395-401, https://doi.org/ 10.1016/j.jpba.2018.11.014.

26. Marie P, Christophe C, Manon R, Marc M, Charleric B, Patrice V. Environmental monitoring by surface sampling for cytotoxics: a review. Environ Monit Assess. 2017;189(2): 52, https://doi.org/10.1007/s10661-016-5762-9.

27. Sessink PJ, Kroese ED, van Kranen HJ, Bos RP. Cancer risk assessment for health care workers occupationally exposed to cyclophosphamide. Int Arch Occup Environ Health. 1995;67:317-23.

28. Hedmer M, Wohlfart G. Hygienic guidance values for wipe sampling of antineoplastic drugs in Swedish hospitals. J Environ Monit. 2012;14:1968-75, https://doi. org/10.1039/2em10704j.

29. Sottani C, Grignani E, Oddone E, Dezza B, Negri S, Villani $\mathrm{S}$, et al. Monitoring surface contamination by anti-neoplastic drugs in Italian hospitals: Performance-based hygienic guidance values (HGVs) project. Ann Work Expo Health. 2017;61(8):994-1002, https://doi.org/10.1093/ annweh/wxx065.

30. Hon CY, Teschke K, Demers PA, Venners S. Antineoplastic drug contamination on the hands of employees working throughout the hospital medication system. Ann Occup Hyg. 2014;58(6):761-70, https://doi.org/10.1093/ annhyg/meu019.

31. Koller M, Böhlandt A, Haberl C, Nowak D, Schierl R. Environmental and biological monitoring on an oncology ward during a complete working week. Toxicol Lett. 2018;298:158-63, https://doi.org/10.1016/j.toxlet.2018. 05.002 .

32. Caruso A, Vigna C, Bigazzi V, Sperduti I, Bongiorno L, Allocca A. Burnout among physicians and nurses working in oncology. Med Lav. 2012;103(2):96-105.

This work is available in Open Access model and licensed under a Creative Commons Attribution-NonCommercial 3.0 Poland License - http://creativecommons.org/licenses/by-nc/3.0/pl/deed.en. 